\title{
A Hybrid Reactive Distillation Process with High Selectivity Pervaporation for Butyl Acetate Production via Transesterification
}

\author{
Gregorius Rionugroho Harvianto ${ }^{\mathrm{a}}$, Faizan Ahmad ${ }^{\mathrm{b}}$, Moonyong Lee a, * $^{\mathrm{a}}$ \\ grharvianto@ynu.ac.kr, faizan615@gmail.com, mynlee@ynu.ac.kr
}

aProcess Systems Design and Control Laboratory, School of Chemical Engineering,

Yeungnam University, Gyeongsan 712-749, Republic of Korea

${ }^{\text {bS }}$ chool of Science and Engineering, Teesside University, Middlesbrough, United Kingdom

Submitted to Journal of Membrane Science

Address: School of Chemical Engineering, Yeungnam University, Dae-dong 214-1,

Gyeongsan 712-749, Republic of Korea

*Correspondence concerning this article should be addressed to:

Prof. Moonyong Lee

E-mail: mynlee@yu.ac.kr

Phone: +82538103241

Fax: +82538113262 


\section{Abstract}

A hybrid reactive distillation system with high selectivity pervaporation was examined to produce butyl acetate and methanol via transesterification of methyl acetate with butanol. High selectivity pervaporation was combined with reactive distillation to eliminate a hitherto required column for the separation of a methanol and methyl acetate azeotrope. The polyamide- 6 membrane was used for this purpose because of its high selectivity for methanol while also allowing sufficient permeate flux. The high purity methyl acetate recovered in the retentate stream leads to high conversion in the reactive distillation column, which enhances the energy savings (up to $71 \%$ ) of this process. The feasibility of the proposed hybrid processes and several alternative designs were evaluated by rigorous simulation and optimization using the Aspen Plus software package. The effects of several designs and operating variables were also investigated for the proposed design. The high potential of the hybrid reactive distillation and pervaporation system for butyl acetate production is very promising; it may not only reduce the total annual costs relative to conventional systems but may also provide an attractive strategy to address problems associated with methanol and methyl acetate azeotropes in the effluent generated in the polyvinyl alcohol industry.

Keywords: reactive distillation; pervaporation; hybrid process; butyl acetate production; energy savings 


\section{Introduction}

Butyl acetate (BuAc) is used widely as a raw material in the coating and painting industries. In addition, BuAc is also a good solvent for manufacturing lacquers, acrylic polymers, enamels, vinyl resins, and nitrocellulose [1]. Due to its low toxicity and relatively small environmental impact, BuAc has become a more favorable solvent to replace other more toxic and teratogenic solvents such as ethoxy ethyl acetate. Moreover, it has been used as a synthetic fruit flavoring in food products, in the pharmaceutical industry, and in a variety of cosmetic formulations [2]. In 2008, the annual US consumption of BuAc was reported to be 105,000 metric tons [3]. BuAc is usually produced via the esterification reaction of butanol $(\mathrm{BuOH})$ with acetic acid using sulfuric acid as the catalyst [4]. However, such esterification reactions can be problematic because of the inevitable problems associated with using homogeneous catalysts [5]. For this reason, alternative processes that use heterogeneous catalysts, which may lead to fewer technical issues, are currently being investigated. In the last decade, the utilization of residue from polyvinyl alcohol (PVA) industrial plants as the reactant to synthesize $\mathrm{BuAc}$ by transesterification of $\mathrm{BuOH}$ with methyl acetate $(\mathrm{MeAc})$ has attracted significant attention.

MeAc is obtained as a by-product in the production of PVA as approximately 1.68 times the PVA product by weight. Previously, MeAc was disposed of as waste or was sold very cheaply $[6,7]$. However, because of recent volatile organic compound (VOC) legislation and its few industrial uses as a solvent, it has become necessary to convert MeAc into a more economically valuable compound. One common approach in the expansion of industrial PVA plants involves the hydrolysis of MeAc into acetic acid and methanol $(\mathrm{MeOH})[7,8]$. However, as discussed by Lin et al. [9], MeAc offers a much economic benefit when it is converted into $\mathrm{BuAc}$ and $\mathrm{MeOH}$ via transesterification with $\mathrm{BuOH}$. Notably, the $\mathrm{MeOH}$ that is obtained as the by-product from either hydrolysis or transesterification is recycled back to 
the production of PVA. For instance, in a medium industrial plant that produces PVA in Niigata, Japan, it was projected that the difference in annual revenues would be $\$ 11,750,000$ USD in favor of BuAc production since acetic acid has a market price of approximately $\$ 0.75$ $\mathrm{USD} / \mathrm{kg}$ versus the higher price of BuAc (ca. \$1 USD/kg) [10].

Recently, BuAc has been generated by the transesterification reaction of MeAc with $\mathrm{BuOH}$. Several reports studied the kinetics and thermodynamics of this process using Amberlyst-15 as a heterogeneous acid catalyst [11-13]. Jimenez et al. reported the first kinetic data of the transesterification reaction, while also presenting a reactive and extractive distillation (RED) configuration $[6,11]$. However, this innovative process is relatively complex due to the occurrence of two azeotropes, that is, a MeOH-MeAc mixture (66.7 mol\% MeAc) and a BuOH-BuAc mixture $(78.01 \mathrm{~mol} \% \mathrm{BuOH})$. To overcome the azeotrope problem, the RED technique requires an additional component (i.e., xylene) as an extraction solvent. Further, Luyben developed an alternative reactive distillation (RD) process without the requirement of any additional solvent [14], whereas Wang et al. combined the reactive distillation process with a methanol column to reduce the reboiler duty of the distillation columns [15]. Unfortunately, all of these configurations have similar drawbacks since the azeotrope mixture of $\mathrm{MeOH}-\mathrm{MeAc}$ is recycled back to the main reactive distillation column. Note that the recycle stream is necessary to reuse unreacted MeAc while also providing an excess of MeAc as the reactant.

As reported in the experimental and theoretical work by Steinigeweg et al. [12] and Svandova [16], the recycle stream should be concentrated into pure MeAc to increase the conversion of the MeAc. In their work, MeAc is entirely recovered by using a pervaporation membrane. In this low selectivity pervaporation unit, high purity MeAc can be attained in the retentate stream. However, the $\mathrm{MeOH}$ concentration in the permeate stream remains below the product 
specification. Thus, this $\mathrm{MeOH}$-rich stream was then fed to an additional column to recover the pure $\mathrm{MeOH}$ as the product.

The existing reactive distillation-pervaporation hybrid configuration for conventional $\mathrm{BuAc}$ production (via esterification) requires just one reactive distillation column and decanter [2, 17]. However, the current reactive distillation-pervaporation hybrid process (via transesterification) requires an additional $\mathrm{MeOH}$ column as a consequence of the poor $\mathrm{MeOH}$ concentration in the permeate stream. Therefore, for the latter configuration to be competitive, a high selectivity membrane is necessary as a final purification step to attain $\mathrm{MeOH}$ in the outlet stream. High purity $\mathrm{MeOH}$ can be attained in the permeate side of the pervaporation membrane, which would eliminate the need for the $\mathrm{MeOH}$ column. Recently, Abdallah et al. [18] produced a high selectivity pervaporation membrane to separate $\mathrm{MeOH}$ and MeAc. This membrane completely separated $\mathrm{MeOH}$ from $\mathrm{MeOH}-\mathrm{MeAc}$ mixtures by pervaporation using a polyamide-6 (PA-6) membrane prepared by a dry-wet phase inversion technique.

In this work, a hybrid reactive distillation system with high selectivity pervaporation was designed for the enhanced production of $\mathrm{BuAc}$ and was sequentially optimized from an economical point of view. To the best of our knowledge, no similar cases of optimal proposed design for BuAc production have been reported in the literature. This type of pervaporation is used to separate the components of an azeotrope in order to increase the conversion as well as to reduce the energy demand of the process. Moreover, the high selectivity pervaporation is necessary to eliminate the need for the hitherto required $\mathrm{MeOH}$ distillation column.

\section{Description of the hybrid reactive distillation system with pervaporation}




\subsection{Reactive distillation}

Conventional chemical plants mainly consist of reaction and separation processes. Reactive distillation is growing as an innovative industrial technology by combining both of these processes into a single comprehensive unit. With this technique, a significant reduction in both energy and equipment costs can be realized. A single reactive distillation column could replace the conventional reactor and distillation processes, which consume five times more energy and capital costs than the single unit alternative [19]. Further, reactive distillation is more advantageous for reversible reaction systems, in which chemical equilibria limit the conversion [6]. Note that continuous removal of products from the reaction chamber favors the reversible reaction toward the product side [20].

In the chemical process optimization software Aspen Plus, simulating reactive distillation can be performed using the distillation model "RadFrac" by specifying the reaction as distinct reactive stages. Kinetic data of the reaction from experimental work is used as input variables in the reaction section of the software. The model is based on a rigorous equilibrium stage model for solving the MESH equations [21]. The number of stages are ordered from top to bottom of the distillation column, with the condenser being the first stage and the reboiler being stage $N$. In "RadFrac," the user must provide the reaction parameters and the reactive stages must be specified with the amount of catalyst hold-up, which differs from the input parameters of conventional distillation. The reaction is combined with the "RadFrac" model, from which Aspen Plus calculates the equilibrium constant by minimizing the Gibbs free energy.

The transesterification reaction of $\mathrm{MeAc}$ and $\mathrm{BuOH}$ is a reversible reaction in the reactive distillation process as:

$$
\text { butanol }+ \text { methyl acetate } \leftrightarrow \text { butyl acetate }+ \text { methanol }
$$


Strong acids must be used to catalyze this reaction. The kinetic data for the Amberlyst-15 ion exchange resin as a catalyst were reported by Jimenez et al. [11] by assuming a catalyst bulk density of $2000 \mathrm{~kg} / \mathrm{m}^{3}$. The kinetic expressions used are given as follows:

$$
\begin{gathered}
r=k_{f} C_{n-\mathrm{BuOH}} C_{\mathrm{MeAc}}-k_{r} C_{\mathrm{BuAC}} C_{\mathrm{MeOH}} \\
k_{f}=7 \times 10^{8} \exp \left(\frac{71960}{R T}\right) ; k_{r}=9.467 \times 10^{8} \exp \left(\frac{72670}{R T}\right)
\end{gathered}
$$

where $r$ is the overall reaction rate with concentration in molality $\left(\mathrm{kmol} / \mathrm{m}^{3}\right) ; k_{f}$ and $k_{r}$ are the forward and backward reaction constants $\left(\mathrm{kmol} / \mathrm{s} \cdot \mathrm{m}^{3}\right)$, respectively; $\mathrm{R}$ is the universal gas constant $(8314 \mathrm{~J} / \mathrm{kmol} \cdot$ Kelvin); and $\mathrm{T}$ is temperature (Kelvin). The reaction occurs in the liquid phase. Regarding the reaction rate, an important characteristic of this transesterification reaction is an extremely low equilibrium constant, which favors reactive distillation.

An appropriate thermodynamic model is essential to create a reliable process design. In this quaternary system, the UNIQUAC [22] model has used for the vapor-liquid equilibrium (VLE) calculations. All of these VLE binary interaction parameters are available in the Aspen Plus simulator. The UNIQUAC model was used because the interaction parameters can be fitted simultaneously to different types of phase equilibrium data, which were taken from the Dortmund Data Bank [12]. Additionally, this model is useful because it accurately describes the chemical equilibria and reaction kinetics. Note that vapor phase non-idealities have been neglected during the VLE calculations because of the relatively low pressure (1 atm) required in the proposed design [12].

\subsection{Pervaporation}

Separation using a pervaporation membrane has recently gained increasing attention in the chemical industry. Pervaporation offers the superior advantage of overcoming certain thermodynamic separation limitations such as treating close boiling and azeotropic mixtures. Instead of the distillation technique, pervaporation (or vapor permeation) of organic mixtures 
has been discussed at length by numerous researchers and is well documented as a low energy consumption separation process $[23,24]$. In pervaporation, the component with the highest permeation ability favorably passes through the membrane and is continuously withdrawn in the form of vapor from the permeate side of the membrane. The continuous removal of the vaporous permeate generates a concentration gradient across both sides of the pervaporation membrane, which acts as the driving force for the process. To enhance its applicability and commercialization, pervaporation membranes have been hybridized with conventional distillation processes in order to obtain desired separation efficiencies [24-26]. Moreover, the hybrid application of pervaporation with reactive distillation gives access to a variety of innovative process concepts [27, 28].

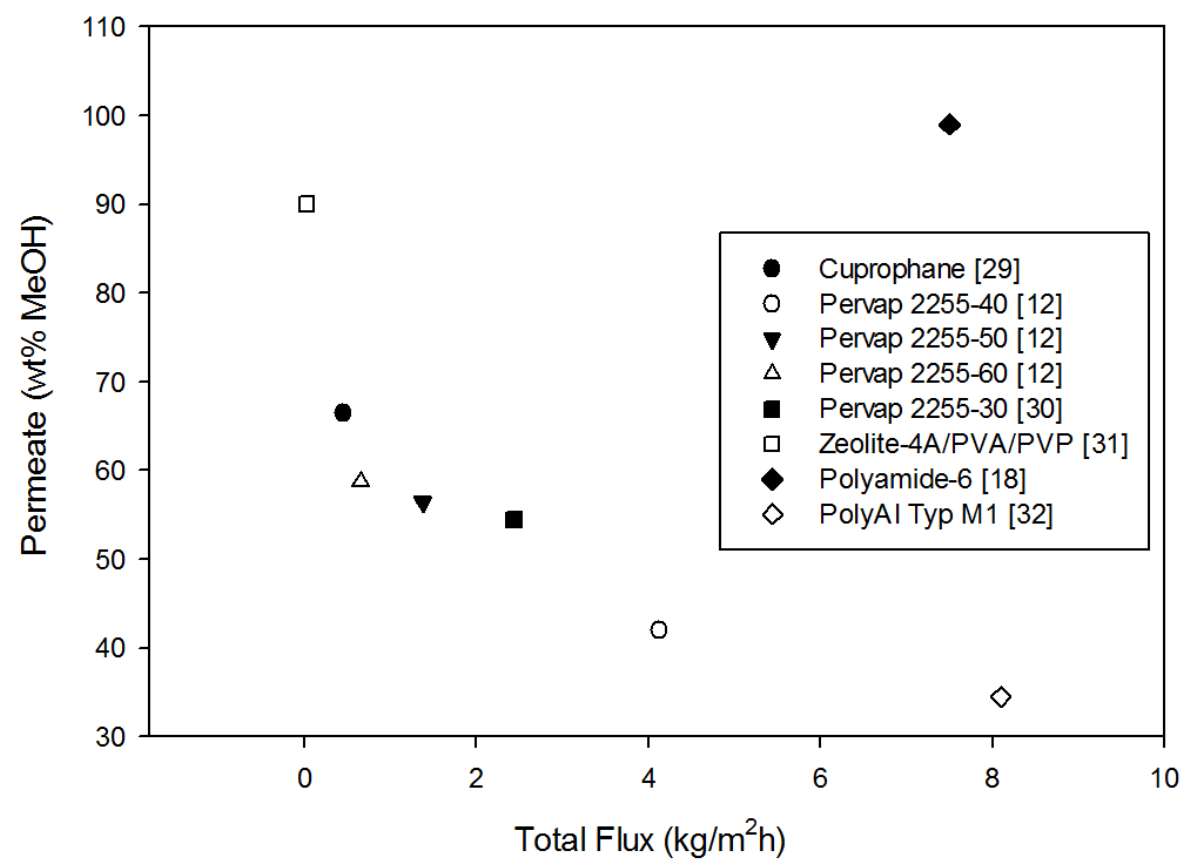

Fig. 1. Flux and permeate data of pervaporation for methanol-methyl acetate separation at the same feed composition (20 wt $\% \mathrm{MeOH})$.

From the literature, it is clear that use of pervaporation membranes is an effective technique to separate $\mathrm{MeOH}$ from MeAc by overcoming the azeotrope problem. Fig. 1 summarizes the performances of the available hydrophilic pervaporation membranes that have been used to 
separate $\mathrm{MeOH}-\mathrm{MeAc}$ mixtures [12, 18, 29-32]. These hydrophilic membranes are $\mathrm{MeOH}-$ selective, enabling high concentrations of $\mathrm{MeOH}$ to be obtained in the permeate stream. The feed composition used for comparison in Fig. 1 is the azeotrope composition of $\mathrm{MeOH}-$ MeAc. The detailed flux and permeate concentrations at the different feed compositions of various commercial and lab-based synthesized membranes for $\mathrm{MeOH}-\mathrm{MeAc}$ pervaporation have been reported earlier [33].

However, most of these membranes are limited at producing two different products in two output streams because of their low selectivity. Thus, these low selectivity pervaporation membranes can only deliver high purity MeAc in the retentate stream by having a large membrane area. Large membrane areas are required to completely remove the $\mathrm{MeOH}$ in the permeate stream. However, the permeate stream must then go to an adjacent distillation column to separate $\mathrm{MeOH}$ from MeAc. It is conceivable that the addition of such a distillation column may make the system uncompetitive with a hybrid reactive distillation with pervaporation for BuAc production via esterification, which requires only a reactive distillation column and a decanter [17].

Nevertheless, it is without question that additional advantages will be realized if a membrane with high selectivity performance, such as Zeolite-4A/PVA/PVP [31] and PA-6 [18], can be effectively utilized. Indeed, the limitation of two pure products in the retentate and permeate streams could be eliminated with the implementation of a high selectivity membrane. Until now, the PA-6 membrane has been the only membrane capable of completely separating $\mathrm{MeOH}-\mathrm{MeAc}$ mixtures through pervaporation; high purity $\mathrm{MeOH}$ could be obtained in the permeate stream, whereas high purity MeAc was removed from the retentate stream. From a literature survey, PA-6 has been shown to perform well in numerous separation processes such as water-ethanol [34], water-dioxane [35], acetic acid-water [36], phenol-water [37], and water-MeOH [38]. In addition, PA-6 has been used successfully in organic-organic 
separations to remove $\mathrm{MeOH}$ from methyl-tert butyl ether and dimethyl carbonate mixtures by pervaporation [39].

\subsection{Hybrid process of reactive distillation with low and high selectivity pervaporation}

This work aims to evaluate the performance of a hybrid process by focusing on the potential of using a high selectivity membrane. With the high selectivity membrane, the placing of pervaporation is aimed to provide nearly-pure methyl acetate in the retentate stream. The high purity of methyl acetate in retentate stream can be obtained by having sufficient membrane area, for allowing all methanol pass through the membrane, which can be designed and calculated dependent on feed composition and flow rate. The process design approach used here is same with the work by Steinigeweg and Gmehling [12] to obtain the pure methyl acetate in retentate stream of pervaporation.

Therefore, the enriched methanol concentration allows the elimination of methanol column required to separate the azeotrope mixtures. For comparison with previous hybrid reactive distillations with low selectivity pervaporation, Pervap 2255-40 [12] has been chosen as a representative membrane because of its moderate flux value and particularly because the high $\mathrm{MeOH}$ concentration from the distillate will be used later as the membrane feed. It has previously been reported that the best choices in this regard are either the PA-6 or Pervap 2255-40 membranes, given the medium-high concentration range of $\mathrm{MeOH}$ as the membrane feed [33].

In this study, the hybrid reactive distillation with high selectivity was simulated using the Aspen Plus software package. A built-in mathematical pervaporation model developed as an Excel-VBA interface was used to examine the pervaporation process. This model can be 
integrated with Aspen Plus to determine the pervaporation outlet stream with any number of input variables, which allows complex phenomena to be simulated. The input variables of the model include the permeability data of methyl acetate and methanol as a function of their concentration in the feed stream, membrane thickness, and permeate pressure. Each experimental dataset has a different membrane thickness, operating condition, and feed composition. Table 1 lists the input variables obtained from the published literature at the same feed composition $(20 \mathrm{wt} \%$ of $\mathrm{MeOH})$. The detailed necessary input variables of the model for the different feed concentration can be derived from the data in each literature $[12$, $18]$.

Table 1. Pervaporation specifications for methanol-methyl acetate separation at the same feed composition $(20 \mathrm{wt} \%$ of $\mathrm{MeOH})$

\begin{tabular}{|c|c|c|}
\hline Variable & $\begin{array}{l}\text { Low selectivity } \\
\text { [12] }\end{array}$ & $\begin{array}{l}\text { High selectivity } \\
\text { [18] }\end{array}$ \\
\hline Membrane thickness (meter) & $1 \times 10^{-6}$ & $4 \times 10^{-4}$ \\
\hline Permeability of methanol ( $\mathrm{kmol} / \mathrm{m} \mathrm{h}$ bar) & $2.92 \times 10^{-10}$ & $1.67 \times 10^{-7}$ \\
\hline Permeability of methyl acetate $(\mathrm{kmol} / \mathrm{m} \mathrm{h}$ bar) & $3.74 \times 10^{-9}$ & $2.42 \times 10^{-10}$ \\
\hline Feed pressure (bar) & 1.013 & 1.013 \\
\hline Permeate pressure (bar) & $7 \times 10^{-3}$ & 0.2 \\
\hline
\end{tabular}

This model also utilizes the capabilities of Aspen Plus to calculate the mass and energy balances for application in the process flowsheet. The built-in mathematical for modeling multicomponent pervaporation process, which were based on a solution-diffusion model used previously to examine hybrid distillation membranes, were used and validated to model the pervaporation under different feed conditions [25]. By employing the solution-diffusion 
model, the permeate components dissolve in the membrane material and further diffuse through the membrane along a concentration gradient. Separation occurs due to the difference in rates of diffusion that each component through the membrane's material as well as the solubility of each component in the membrane's material. For each hybrid design examined in this work, the required membrane area for pervaporation was designed with the requirement of $99.9 \mathrm{~mol} \% \mathrm{MeAc}$ in the retentate, which was ensured by using the flowsheet design specification function in Aspen Plus.

\section{Evaluation of alternative designs}

\subsection{Design of a conventional reactive distillation process}

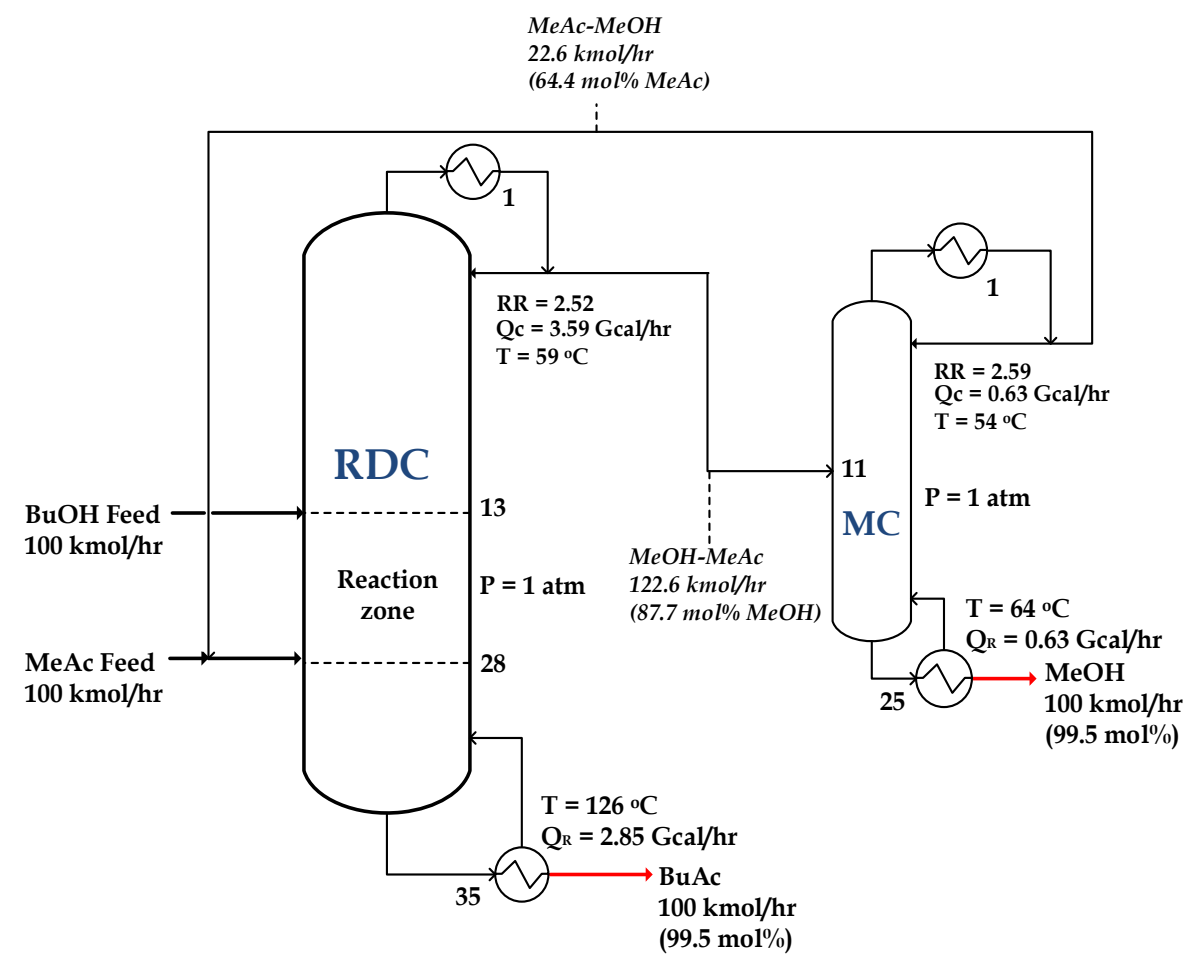

Fig. 2. Conventional reactive distillation process.

Conventional reactive distillation process consists of a reactive distillation column (RDC) 
and a methanol column (MC). The reactive distillation column is divided into three sections or zones: rectifying, reactive, and stripping. The feed, product specifications, distillation column conditions, and the amount of catalyst were considered to be identical as those used in the previous study of conventional reactive distillation process [40]. As reactants, $\mathrm{BuOH}$ and MeAc are fed into the reactive distillation column at a flow rate of $100 \mathrm{kmol} / \mathrm{h}$ on the top and bottom of the reactive section. The amount of catalyst used in this design was 500 $\mathrm{g} /$ stage. To maintain the stability of the Amberlyst-15 catalyst, the reaction zone temperature must be less than $120{ }^{\circ} \mathrm{C}$ [41]. For this reason, the reactive distillation column was operated at 1 atm. BuAc (99.5 mol\%) is taken from the bottom of the reactive distillation column as the product. Unreacted MeAc and by-product $\mathrm{MeOH}$ was taken as the distillate and proceed to the rectifying section as feed for the methanol column to separate $\mathrm{MeOH}$ from the $\mathrm{MeOH}-$ MeAc mixture. Thus, the bottom stream of the methanol column is $99.5 \mathrm{~mol} \% \mathrm{MeOH}$. Nevertheless, due to the azeotropic nature of the mixture, the distillate from the methanol column is an azeotropic mixture of $\mathrm{MeOH}-\mathrm{MeAc}$ and is recycled back to the reactive distillation column. Fig. 2 presents the detailed configuration of a conventional reactive distillation process with a total reboiler duty of $3.48 \mathrm{Gcal} / \mathrm{h}$. The number of stages in the rectifying, reaction, and stripping sections are 12,16 , and 7 , respectively. The allocation of a number of stages in this configuration is taken from the work of Wang et al., who claimed that this configuration is optimal for the reactive distillation process [40]. Therefore, this configuration is considered as the benchmark for the subsequent hybrid designs explored in this work.

\subsection{Design of a reactive distillation with low selectivity pervaporation}

Due to a large amount of energy required for conventional reactive distillation processes, several researchers have suggested alternative design to reduce the associated operating costs. 
Designs of a conventional reactive distillation with a pervaporation membrane have been reported by Steinigeweg et al. [12] and Svandova et al. [16]. Based on their experimental work, both groups claimed that high reaction conversion occurs after $\mathrm{MeOH}$ is removed from the recycle stream. Using the same number of stages for the reactive distillation and methanol columns as the benchmark case (see Section 3.1), Fig. 3 shows the configuration of a hybrid reactive distillation with low selectivity pervaporation. Compared with the benchmark case, the total reboiler duty of the process decreases from $3.48 \mathrm{Gcal} / \mathrm{h}$ to $2.02 \mathrm{Gcal} / \mathrm{h}$. Notably, the azeotropic composition of the recycle stream, which is the main obstacle to attain high purity MeAc, was successfully avoided. This can be achieved by placing the pervaporation process between the reactive distillation and methanol columns. Therefore, conversion of $\mathrm{BuOH}$ to $\mathrm{BuAc}$ is improved significantly once the nearly pure MeAc in the recycle stream is provided [12], as indicated in Fig. 4 by the product composition profile along the reactive distillation column. Fig. 4 shows that the BuAc purity at the end of the reactive section improves from 81.7 to $89.6 \mathrm{~mol} \%$ by the addition of the pervaporation membrane. With a high concentration of BuAc in the stripping zone, the required reboiler duty of the reactive distillation could be reduced significantly. Therefore, the results suggest that the hybrid reactive distillation configuration with low selectivity pervaporation can provide energy savings (of up to $42 \%$ ) for BuAc production.

This hybrid process used low selectivity pervaporation, which does not facilitate purity specification of $\mathrm{MeOH}$ in the permeate stream. Therefore, as shown in Fig. 3, it is necessary to separate the $\mathrm{MeOH}-\mathrm{MeAc}$ mixture from the permeate stream in the methanol column, which is similar to the process employed in conventional reactive distillation systems. $\mathrm{MeOH}$ with the product specification is removed from the bottom stream of the methanol column. The distillate stream of the methanol column is then recycled back to the pervaporation unit since it consists of the azeotropic $\mathrm{MeOH}-\mathrm{MeAc}$ mixture. For this reason, high selectivity 
pervaporation is proposed for this system to overcome the aforementioned problems. It is expected that this approach will solve the azeotropic problems. Notably, higher energy and cost savings could be realized using the proposed design.

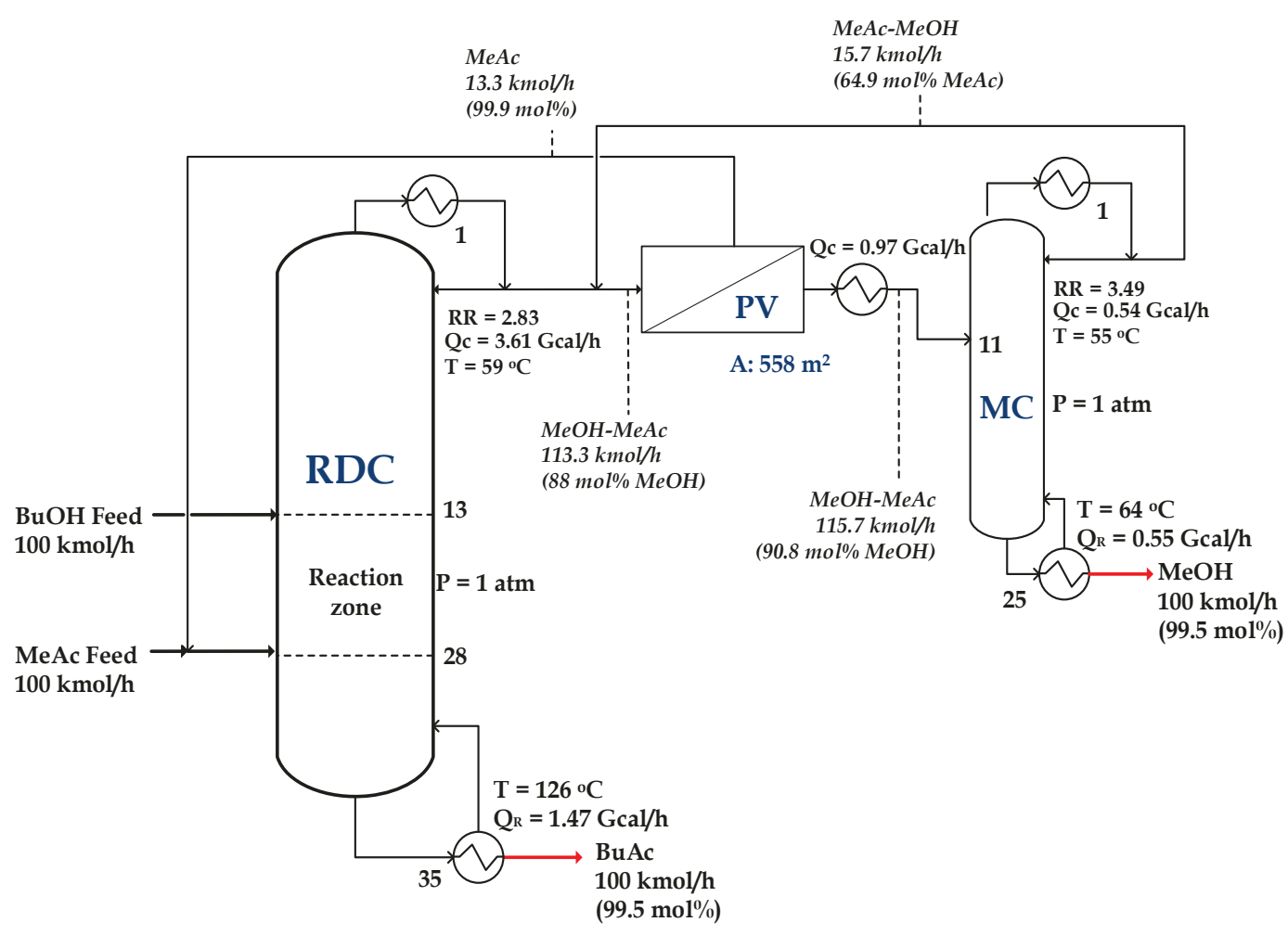

Fig. 3. Hybrid reactive distillation with low selectivity pervaporation.

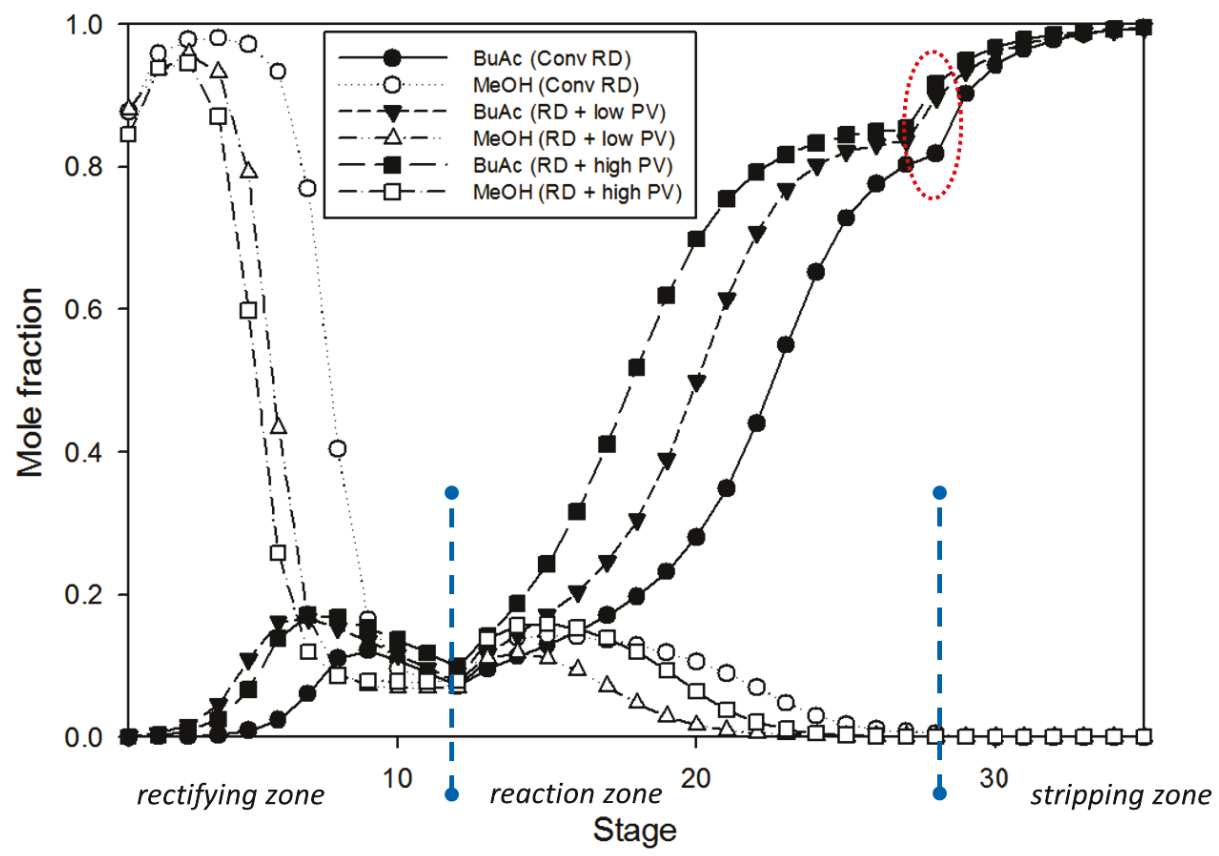


Fig. 4. Product composition profile of a reactive distillation column for all configurations.

\section{Design of a reactive distillation with high selectivity pervaporation}

The industrial production of $\mathrm{BuAc}$, in which esterification of $\mathrm{BuOH}$ with acetic acid is employed, uses a hybrid process involving reactive distillation with pervaporation and the requirement of just one column (i.e., the reactive distillation column) [2, 17]. However, for transesterification reactive distillation with low selectivity pervaporation (as shown in Fig. 3), an additional distillation column (i.e., the methanol column) is required to obtain high purity $\mathrm{MeOH}$. Therefore, the objective of this work is to enhance the commercialization of BuAc production via transesterification by applying a hybrid reactive distillation with high selectivity pervaporation. $\mathrm{MeOH}$ is obtained with high purity $(99.5 \mathrm{~mol} \%)$ in the permeate using such a membrane, suggesting that the methanol column can be safely eliminated from the process, thus reducing its capital and operating costs.

In this section, a new hybrid conventional reactive distillation configuration with a high selectivity membrane is proposed. In order to compare fairly this initial design with alternative configurations, the number of stages in each section of the reactive distillation column was chosen to be identical. Similar to the previous hybrid process, the proposed hybrid configuration (Fig. 5) also attained high purity MeAc (99.9 mol\%) in the retentate stream. Moreover, this proposed configuration obviated the need for the methanol column because the $\mathrm{MeOH}$ specification in the product stream can be fulfilled in the permeate stream. This configuration offers a significant advantage in terms of energy and capital reduction. The results show that the total reboiler duty of the entire transesterification process was reduced significantly from $3.48 \mathrm{Gcal} / \mathrm{h}$ (cf. Fig. 2) to $0.64 \mathrm{Gcal} / \mathrm{h}$. Similar to the hybrid configuration shown in Fig. 3, a reduction of the reboiler duty was realized due to the high 
product conversion at the end of the reactive zone, which was caused by the presence of nearly pure MeAc in the recycle stream. As seen in Fig. 4, BuAc purity up to 91.6 mol\% was achieved at the end of the reactive zone. Moreover, the total reboiler duty was also reduced simply by avoiding the necessity of the methanol column, since high purity $\mathrm{MeOH}$ could be taken as the product from the permeate stream following pervaporation. The observed energy savings (of 64\%) are based on the reactive distillation design of the conventional process presented earlier (see Section 3.1) [40]. The additional energy and cost savings will be possible if further optimization of the proposed hybrid process (i.e., reactive distillation with high selectivity pervaporation) is performed. Such sequential optimization of the proposed hybrid process will be discussed further in the next section.

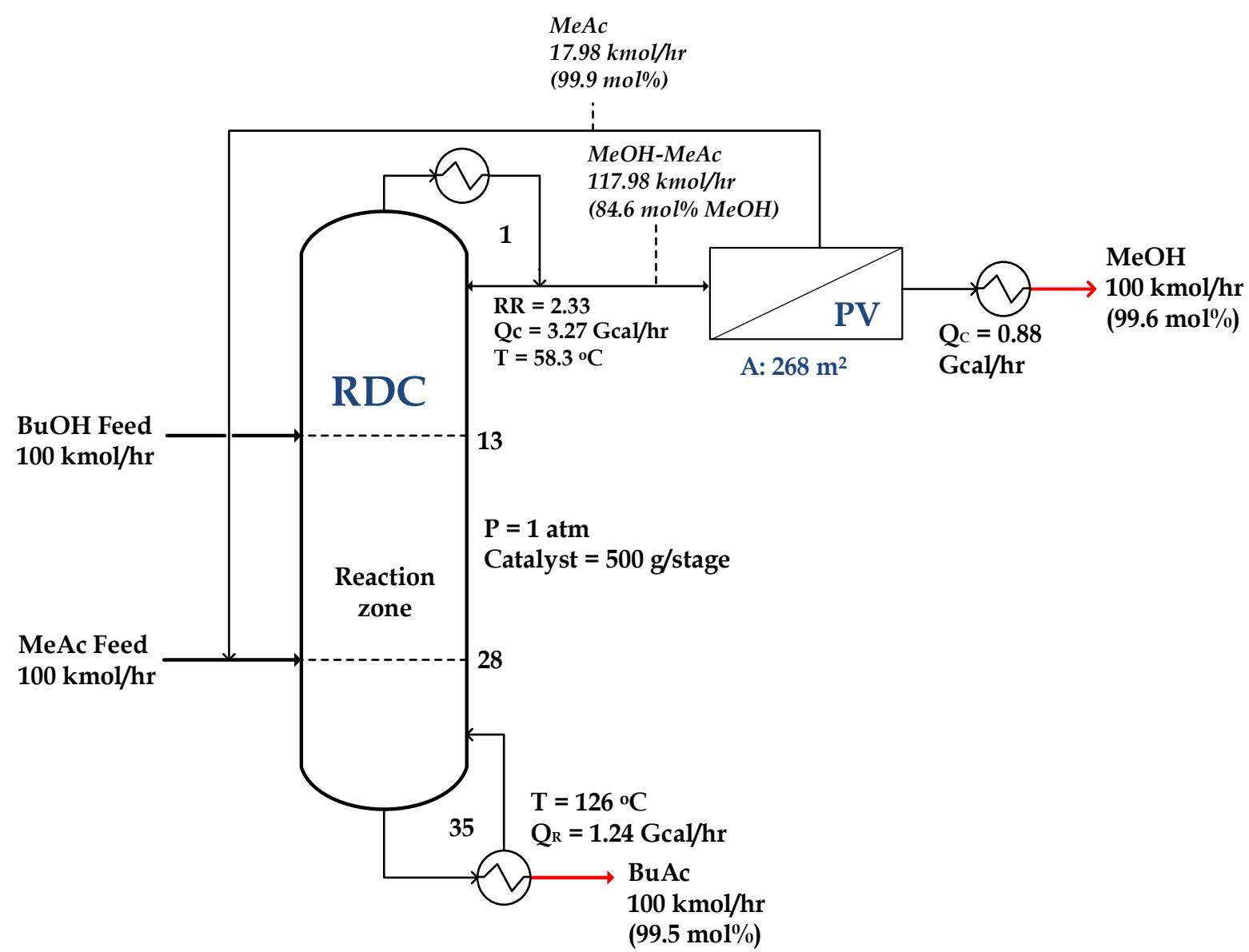


Fig. 5. The initial design of a hybrid reactive distillation with high selectivity pervaporation.

\section{Process optimization method}

Optimization must be performed concomitantly with the process design. An essential aspect of this procedure is a selection of the most significant process variables. In a chemical process, recycle streams between the two unit processes are often incorporated for several purposes: (1) to improve conversion, (2) to minimize the production of undesirable byproducts, (3) to improve energy efficiency, and (4) to improve controllability [20]. The Aspen Plus simulator (v.9) provides a built-in flowsheet optimization function based on the SQP algorithm [21, 42]. The SQP algorithm has become the most successful technique for solving nonlinearly constrained optimization problems [43]. This function helps to minimize the objective function by varying the manipulating variable in the flowsheet. Several investigators have successfully used this optimization approach of Aspen Plus [43-49]. Therefore, all configurations studied in this work have been optimized using the aforementioned optimization tool. In the proposed hybrid process, two degrees of freedom are selected for reactive distillation that will be used in the Aspen Plus simulation: the bottom flow rate and the reflux ratio of the reactive distillation column. Moreover, the proposed hybrid process also has a recycle stream flow (i.e., the retentate stream following pervaporation), which is used as the remaining degree of freedom. The reboiler duty of reactive distillation column was used as the objective function in the optimization procedure, whereas the recycle flow rate and the reflux ratio of the reactive distillation were employed as manipulating variables. Additionally, the product specifications and flow rates were given as constraints. 
The additional total annual cost (TAC) saving was obtained by consideration of the reactive distillation stage structure and several operating variables. Modification of the process includes the number of stages of each section, the catalyst weight, and the retentate concentration. In conjunction with the Aspen Plus optimization function, the sequential optimization procedure is shown in Fig. 6. The alternative designs (see Figs 2 and 3) and the initial design of proposed design (see Fig. 5) also have already been optimized using the Aspen Plus optimization tool but the proposed design is optimized further to obtain an overall optimal design for this system.

The detailed method to calculate the TAC has been provided previously [25]. In addition, in order to highlight the commerciality of the proposed configuration, the price of the commercial PERVAP ${ }^{\circledR}$ membrane used for pervaporation is $\$ 327.6 \mathrm{USD} / \mathrm{m}^{2}$ [50], and further updated via the Chemical Engineering Plant Cost Index of 556.8 (2015) to consider inflation factor to get the idea of prices in recent time. Moreover, in the proposed optimization procedure, the cost of the membrane is simply necessary for comparative evaluation at the conceptual design stage. It should be taken into account that according to different membrane material, the cost of pervaporation membrane should also re-considered once the membrane material produced commercially. The module used in this work was a plate frame module at a price of $\$ 2527.2 \mathrm{USD} /$ module. The area of one membrane module was $50 \mathrm{~m}^{2}$ [50]. The required number of pervaporation modules arranged in a parallel configuration with the equal distribution of feed to each module in proposed hybrid design. The annual maintenance and labor costs of the installations were assumed to be $10 \%$ of the total installation costs [51]. Similar to the commercial membrane, the membrane lifetime was assumed to be two years [50]. Since this work also involves a reaction that requires a catalyst, the operating costs must also include the cost of the catalyst. Therefore, a catalyst life of one 
year was assumed for all of the TAC calculations determined in this work. The catalyst price is $\$ 320 \mathrm{USD} / \mathrm{kg}$, which was obtained from Sigma-Aldrich, United States. 


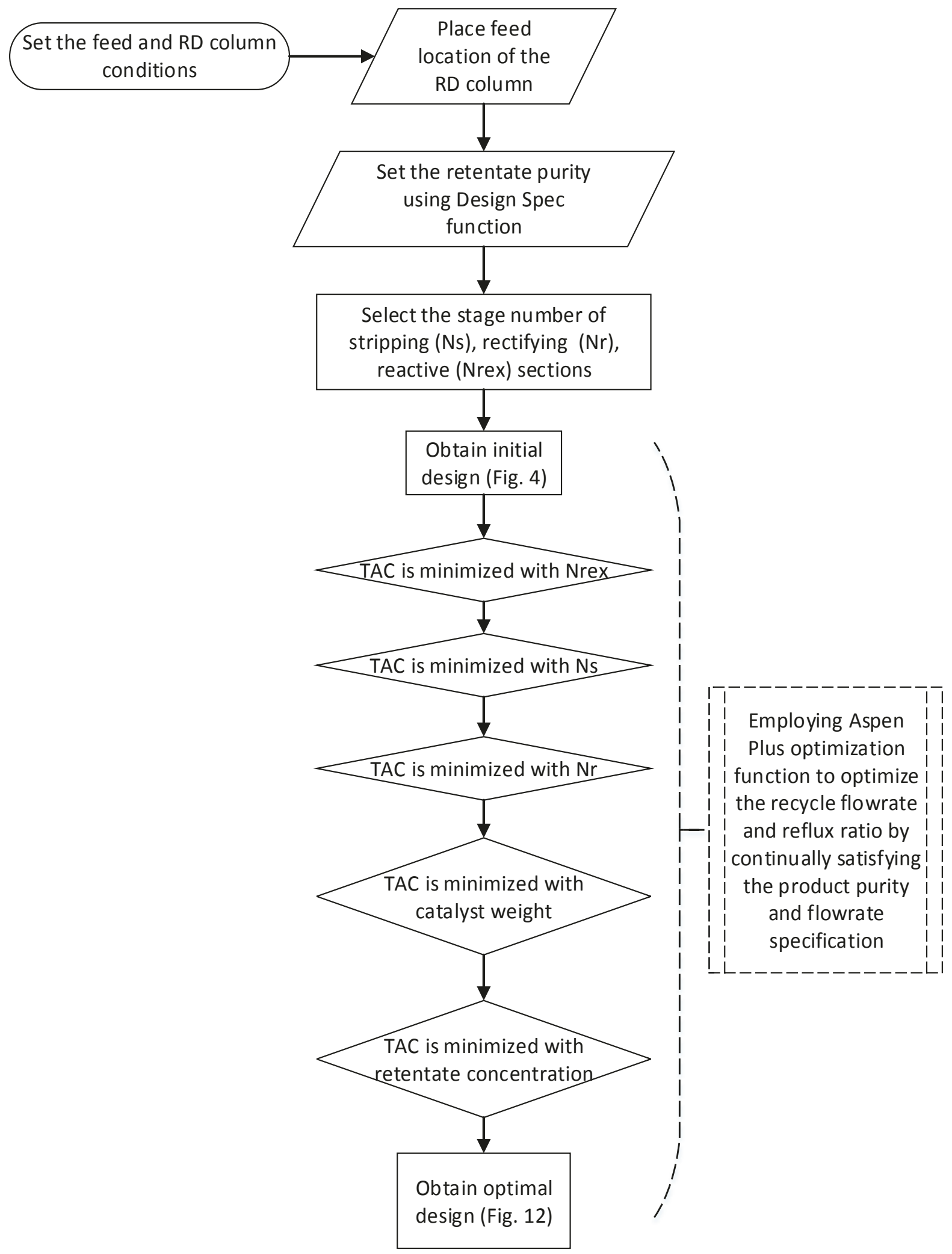

Fig. 6. Sequential optimization of the proposed hybrid process. 


\section{Structure optimization}

\subsection{Effect of reactive stages}

The reactive section is an essential part of the reactive distillation column for the transesterification reaction, which occurs in the presence of a catalyst. Fig. 7 presents the effect of the number of reaction stages on the reactive distillation column performance in terms of the TAC. The feed stream is always introduced at the top and bottom of the reactive section. It is noted that the number of stripping and rectifying stages is kept at the initial design values. Increasing the number of reactive stages increases the reactive hold-up, which lowers the reboiler duty. This result is similar to previous reports of increasing the reactive stages; specifically, the amount of required vapor boil-up decreases to maintain a sufficient amount of product in the bottom stream [20]. However, additional stages result in higher operating costs due to higher condenser duty and an increase in capital cost. According to Fig. 6, 16 reaction stages give a minimum TAC for the hybrid process. From this reason, 16 reaction stages were used in the column configuration for all subsequent simulations.

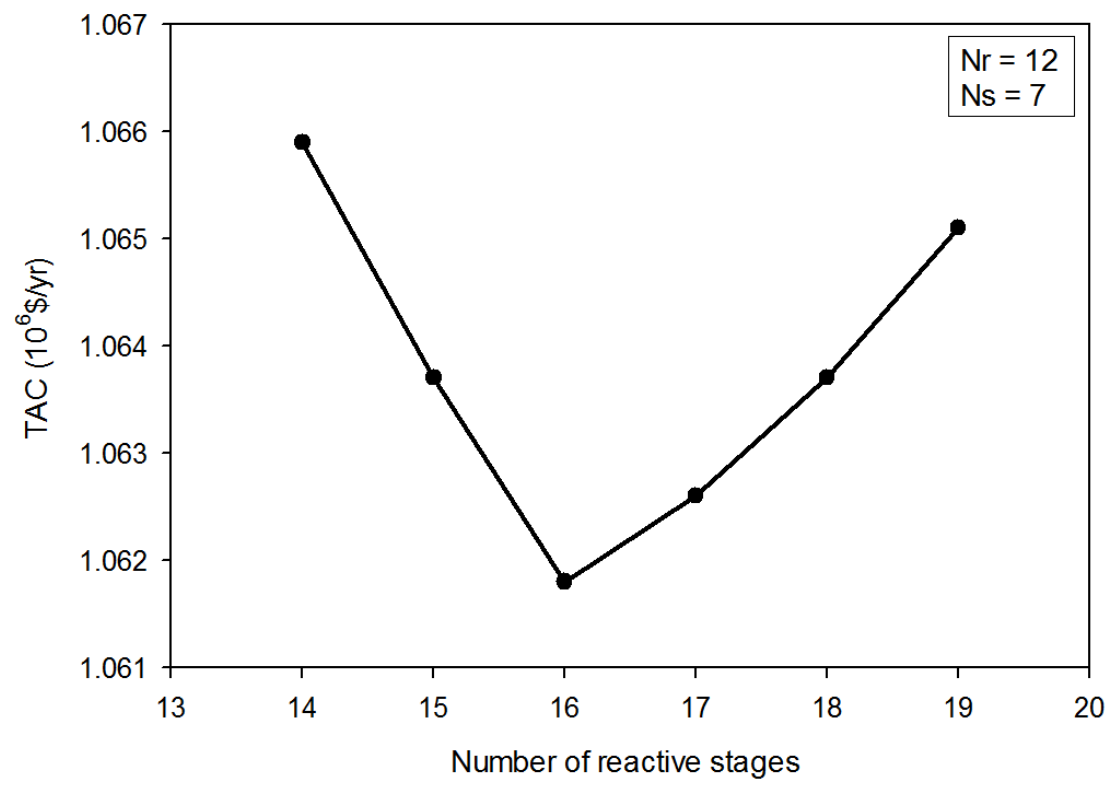

Fig. 7. Effect of the number of reactive stages on the total annual cost of the proposed hybrid process. 


\subsection{Effect of stripping stages}

The stripping stages aim to ensure that a satisfactory separation is achieved, especially to obtain $99.5 \mathrm{~mol} \%$ of BuAc in the bottom product. The present results indicate that the reboiler duty significantly decreases as the number of stripping stages increases, which affected to the significant reduction of operating cost. However, the reduction of the reboiler duty after 13 stages was insignificant. In contrast, increasing the number of stripping stages requires a higher capital cost. Thus, the TAC decreases as the number of stripping stages increases from 7 to 13, as shown in Fig. 8, with the TAC increasing above 13 stages. As a result, the optimal configuration is deemed to include 13 stripping stages.

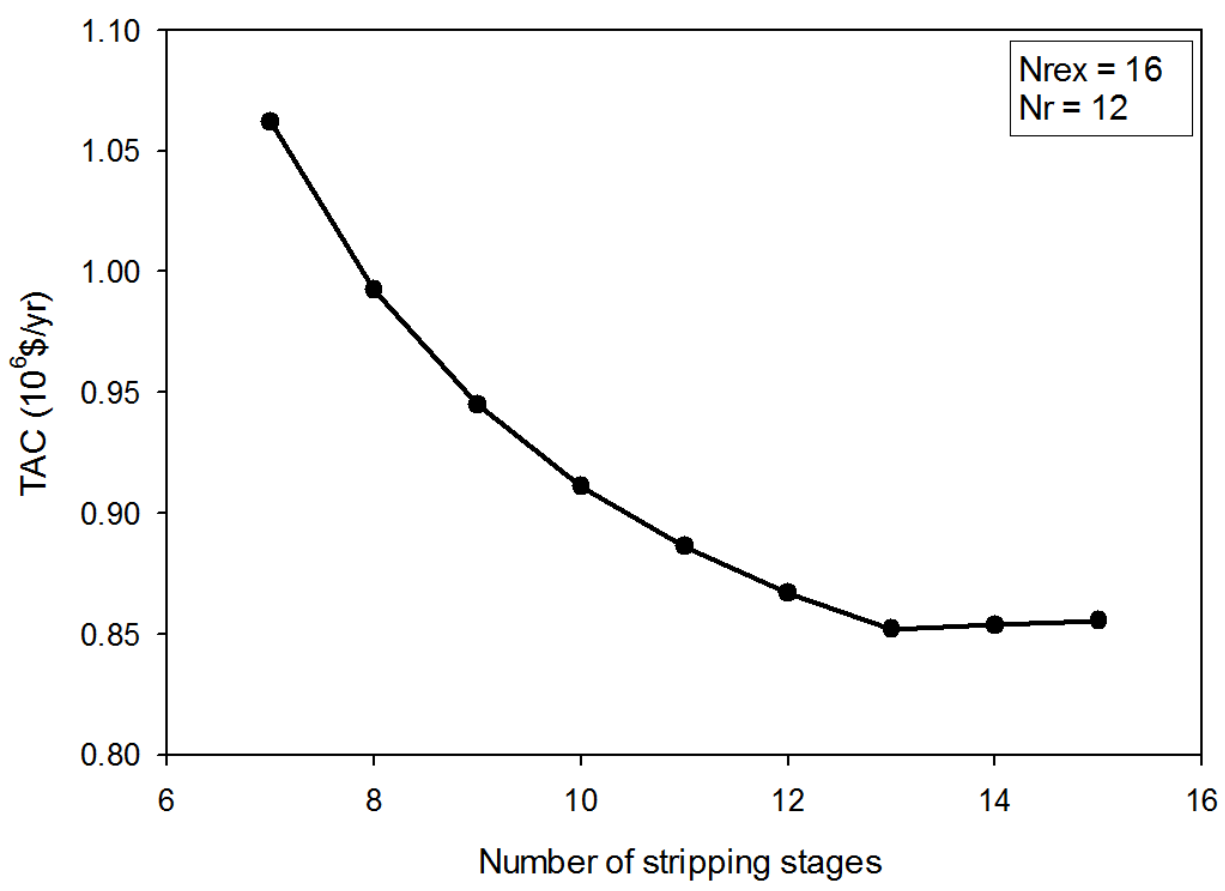

Fig. 8. Effect of the number of stripping stages on total annual cost (TAC) of the proposed hybrid process. 


\subsection{Effect of rectifying stages}

The purpose of the rectifying section in a reactive distillation is to remove light components from the reaction zone. In this transesterification reaction, $\mathrm{MeOH}$ as a by-product is obtained along with unreacted MeAc. The effect of the number of rectifying stages on the TAC of the proposed hybrid process is demonstrated in Fig. 9. As expected, with high purity (or nearly pure) MeAc in the recycle stream, the number of rectifying stages could be reduced since the $\mathrm{MeOH}$ can be completely removed by placing a pervaporation membrane in the distillate stream. The reduction of a number of rectifying stages affected to the lower capital cost of the proposed design. Although product specification could be obtained with fewer rectifying stages, the diameter and condenser duty of the reactive distillation column increases which provide a higher operating and capital costs. Thus, it was found that the minimum TAC was obtained with 8 rectifying stages.

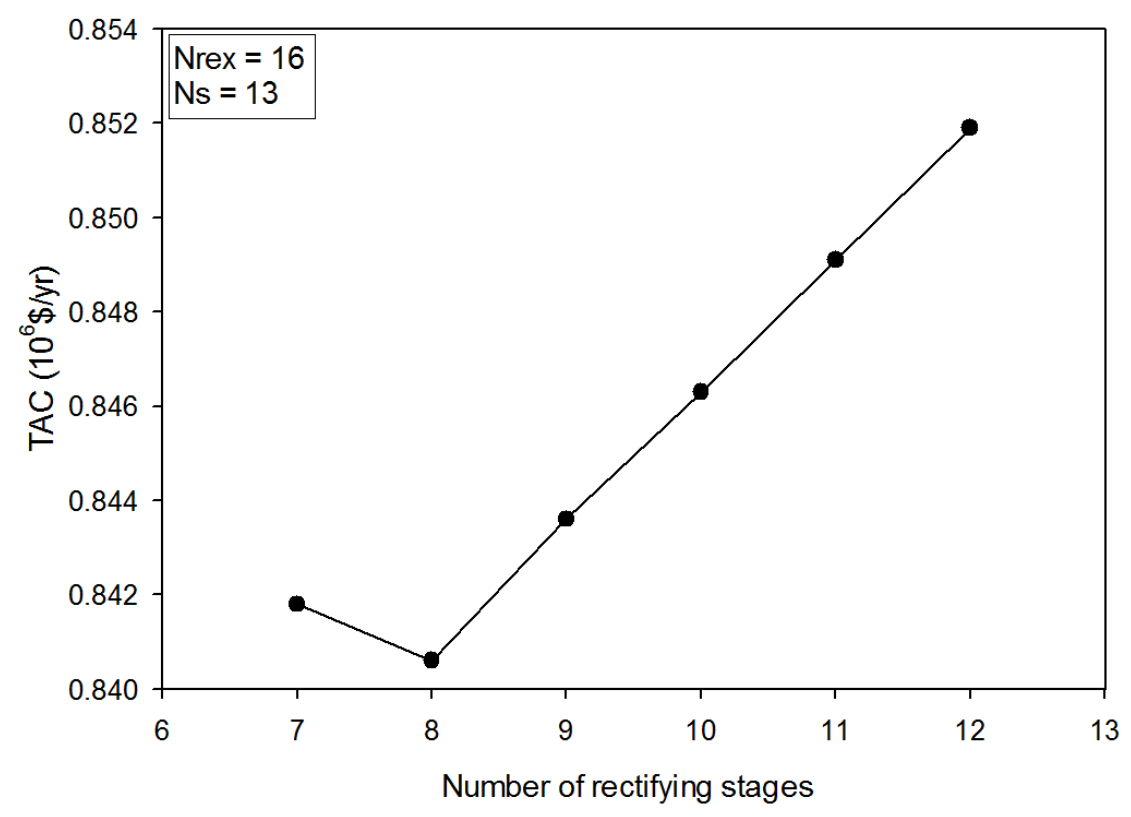

Fig. 9. Effect of the number of rectifying stages on the total annual cost (TAC) of the proposed hybrid process. 


\section{Optimization of operating variables}

\subsection{Effect of catalyst weight}

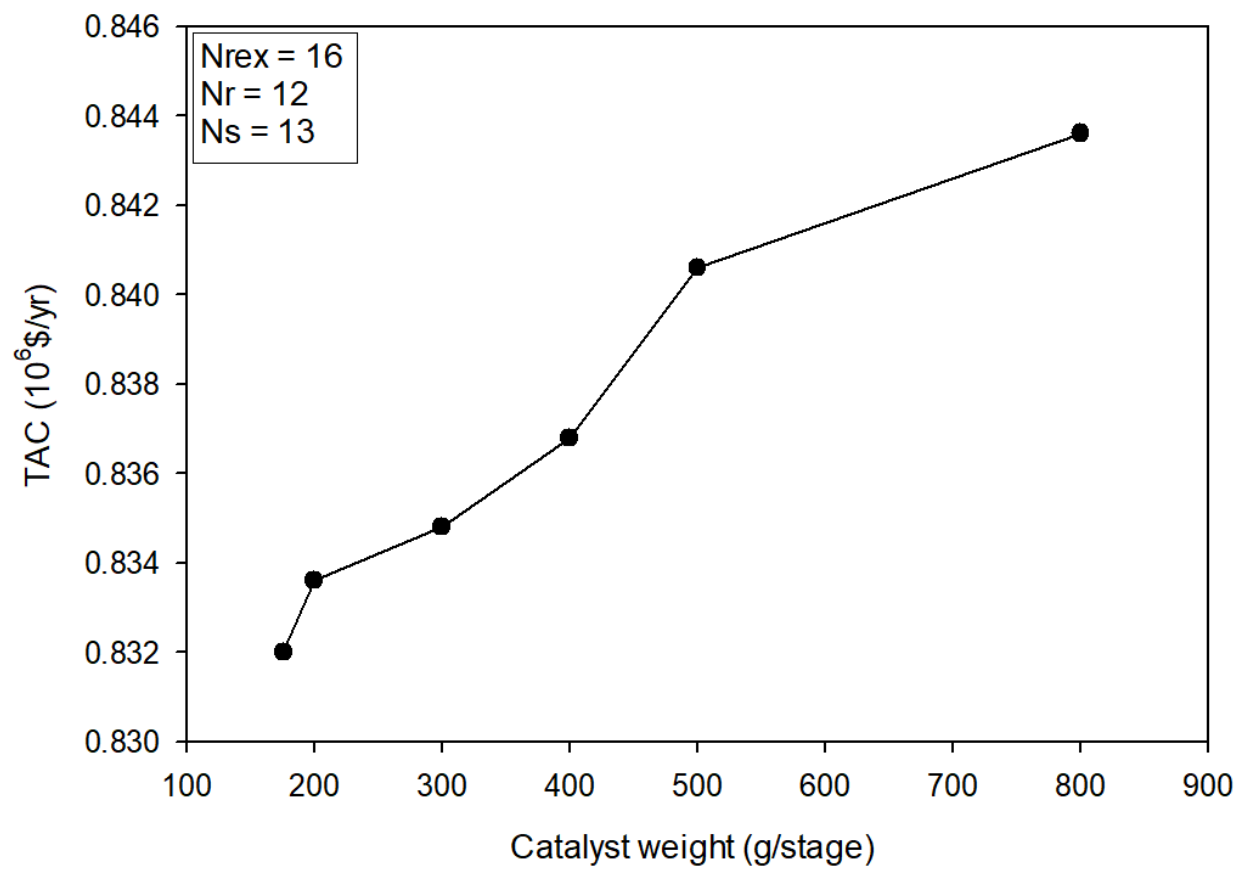

Fig. 10. Effect of the catalyst weight on the total annual cost (TAC) of the proposed hybrid process.

Hold-up is very important in reactive distillation because the reaction rates directly depend on the hold-up (or the amount of catalyst) on each tray [20]. Amberlyst ${ }^{\mathrm{TM}}-15$ is an inexpensive and non-hazardous solid acid that is a useful catalyst. It can be easily handled and is detached from reaction mixtures by simple filtration techniques. Recently, Amberlyst ${ }^{\mathrm{TM}}-15$ has been discovered as a powerful catalyst for numerous organic conversions [52]. With pure MeAc obtained in the retentate stream, it was expected that the amount of catalyst on each tray could be reduced while maintaining the same product specification. However, it is observed that the required conversion and product specification are not attained when the catalyst weight is less than $176 \mathrm{~g}$. Previous reports for this reaction observed that a sufficient amount of catalyst must be available to achieve the desired reaction conversions [13]. An increase in the amount of catalyst has a slight positive effect on reducing the reboiler duty of the reactive 
distillation. However, other factors such as the higher column diameter and catalyst costs must also be considered. As per result, Fig. 10 shows the influence of catalyst weight on the TAC of the hybrid process. The minimum TAC could be obtained by the minimum (or sufficient) amount of catalyst to attain the product specification.

\subsection{Methyl acetate purity in the retentate stream}

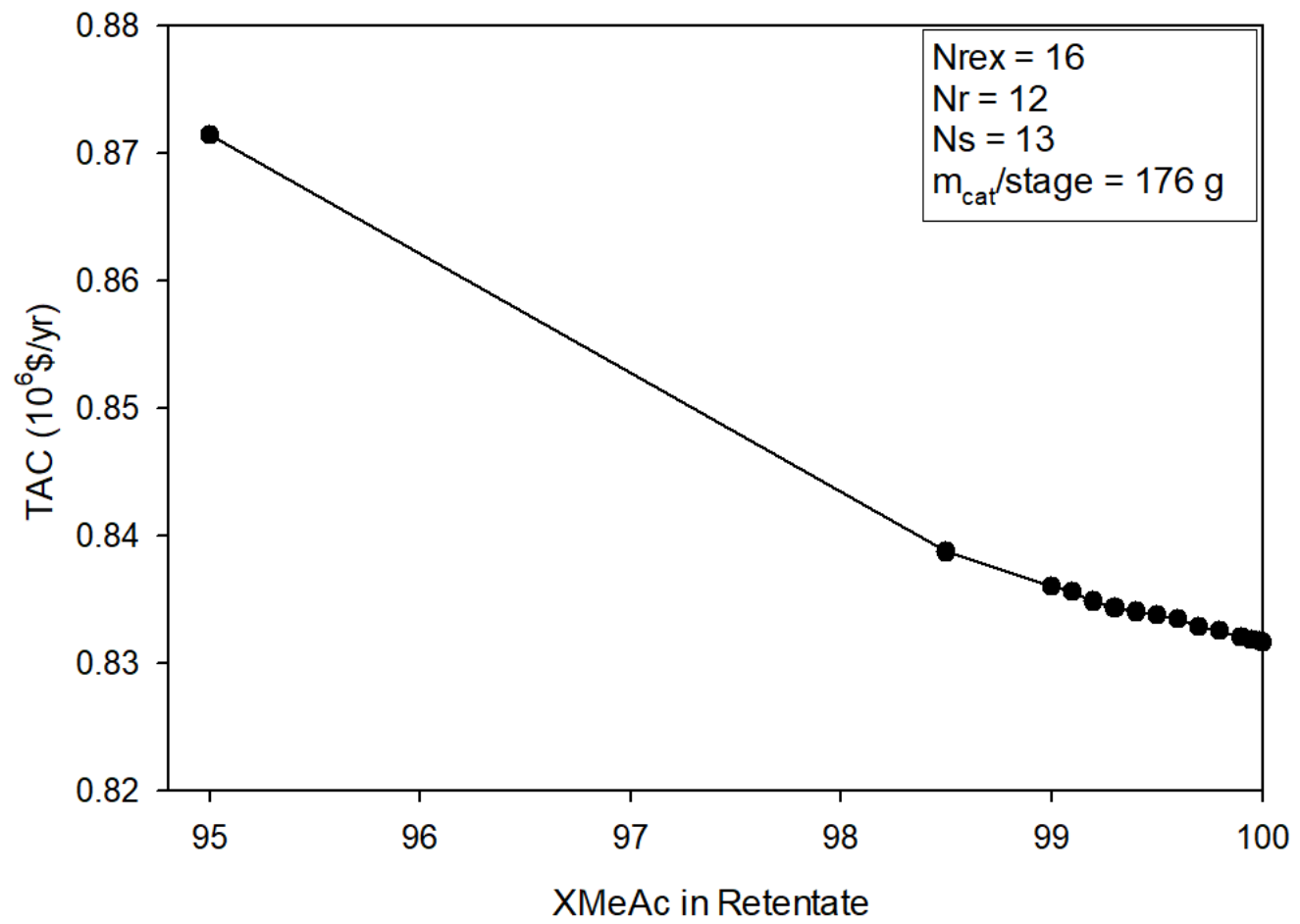

Fig. 11. Effect of methyl acetate concentration in the retentate on the total annual cost (TAC) of the proposed hybrid process.

Since a high selectivity pervaporation was used to obtain MeAc in the retentate stream, the effect of the MeAc concentration on the performance of the hybrid process was studied. Fig. 11 shows that the TAC of the hybrid process decreases as the MeAc concentration in the retentate increases to unity. This indicates that pure MeAc in the retentate is needed for the reaction to proceed in a cost-effective manner. Despite the fact that pure MeAc in the 
retentate requires a slightly larger membrane area, the lower TAC is highly dependent on the significant reduction of condenser and reboiler duty and the reactive distillation column diameter.

Taken together, the optimal structure and its operating variables are summarized in Fig. 12. By combining the high selectivity pervaporation with the reactive distillation column, the most significant optimization outcome of providing pure MeAc in the recycle stream is to minimize the reboiler duty, a number of rectifying stages and the catalyst weight. Notably, employing the proposed optimal configuration may lead to significant reductions of energy (up to $71 \%$ ) and TAC (up to $60 \%$ ) relative to conventional systems.

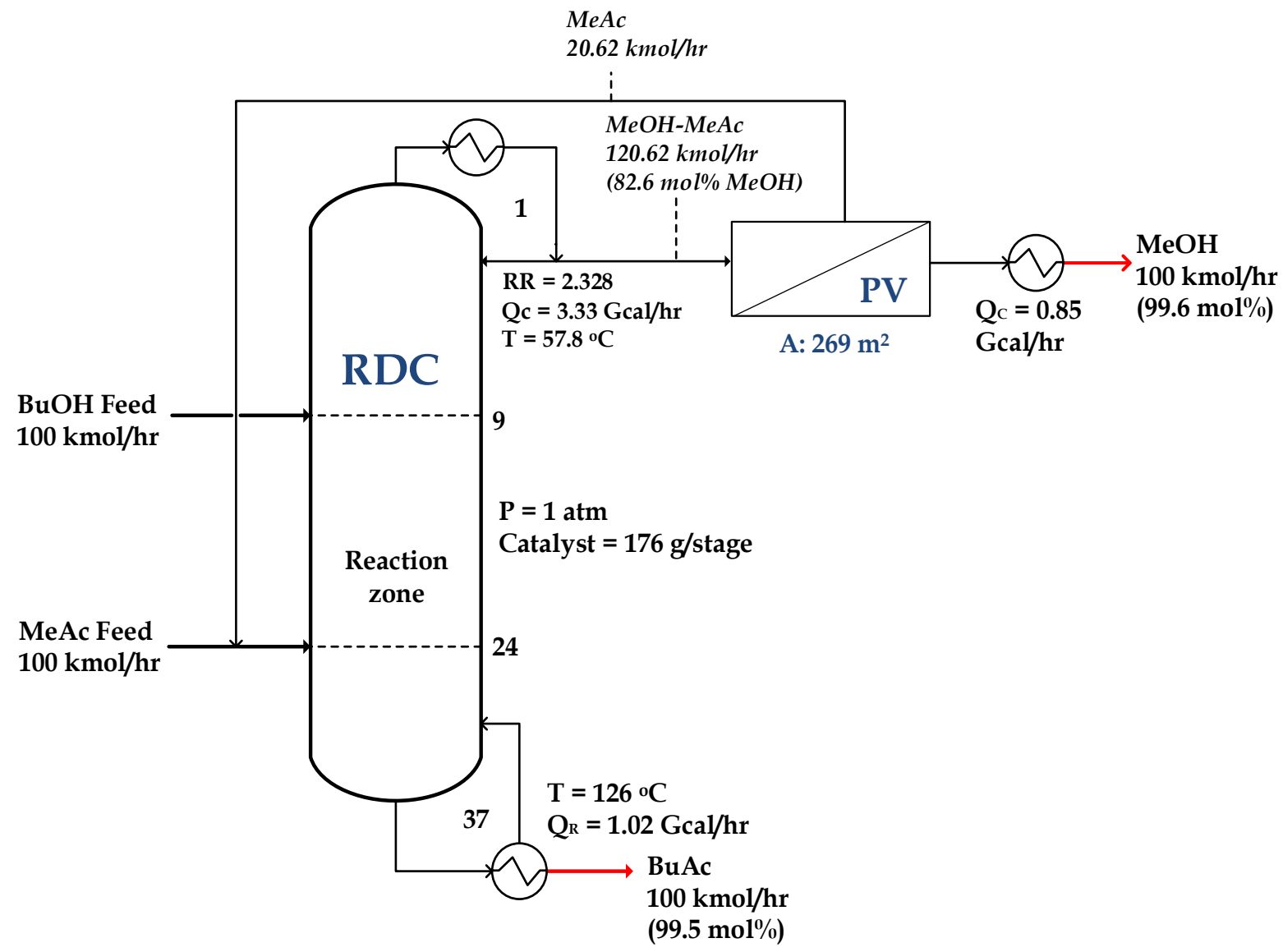

Fig. 12. Optimal configuration of the hybrid reactive distillation system with high selectivity pervaporation. 


\section{Advantages of high selectivity pervaporation in MeOH-MeAc separation}

For specific application in the PVA industry, MM20 (70 wt $\%$ of $\mathrm{MeOH}$ and $30 \mathrm{wt} \%$ of MeAc) is obtained as a by-product during PVA synthesis. According to new legislation on VOCs, it is not possible to sell MM20 as a solvent and it must be considered as waste. Several techniques have been proposed to separate MM20 into two pure products through pressure swing distillation [53] and extractive distillation [54]. As a product, pure MeAc can be used as a reactant for BuAc production. However, the existing technique of $\mathrm{MeOH}-\mathrm{MeAc}$ separation requires high energy and capital costs, and even additional solvents. Therefore, with the availability of high selectivity pervaporation, the retrofit design of MM20 utilization must be considered (Fig. 13). MeAc, which is obtained in the retentate stream of PV-1 (Fig. 13), could be used directly as the feed to the reactive distillation column. Consequently, such a retrofit design will be using the $\mathrm{MeOH}-\mathrm{MeAc}$ azeotrope mixture from the PVA industry as the feed, emphasizing the novel advantages of this hybrid configuration. Moreover, such a scheme will undoubtedly be profitable since the expansion of existing PVA plants would utilize an inexpensive MM20 waste stream.

Finally, this work found the high potential of PA-6 as a high selectivity membrane for $\mathrm{MeOH}-\mathrm{MeAc}$ separation through pervaporation. Note that the PA-6 membrane used in this work was untreated (or unfilled) [18]. To enhance the performance and durability of the membrane during operation, PA-6 could be treated by several techniques during the manufacturing process to increase its selectivity and mechanical stability. Indeed, filling PA6 with low molecular substances to form a mixed-matrix membrane has previously been demonstrated for organic-organic pervaporation applications [39]. Other methods can be considered to improve the structural stability of PA-6 membranes, including thermal 
treatments [55], polyelectrolyte multilayer strategies [56, 57], and cross-linking with other polymers $[58,59]$.

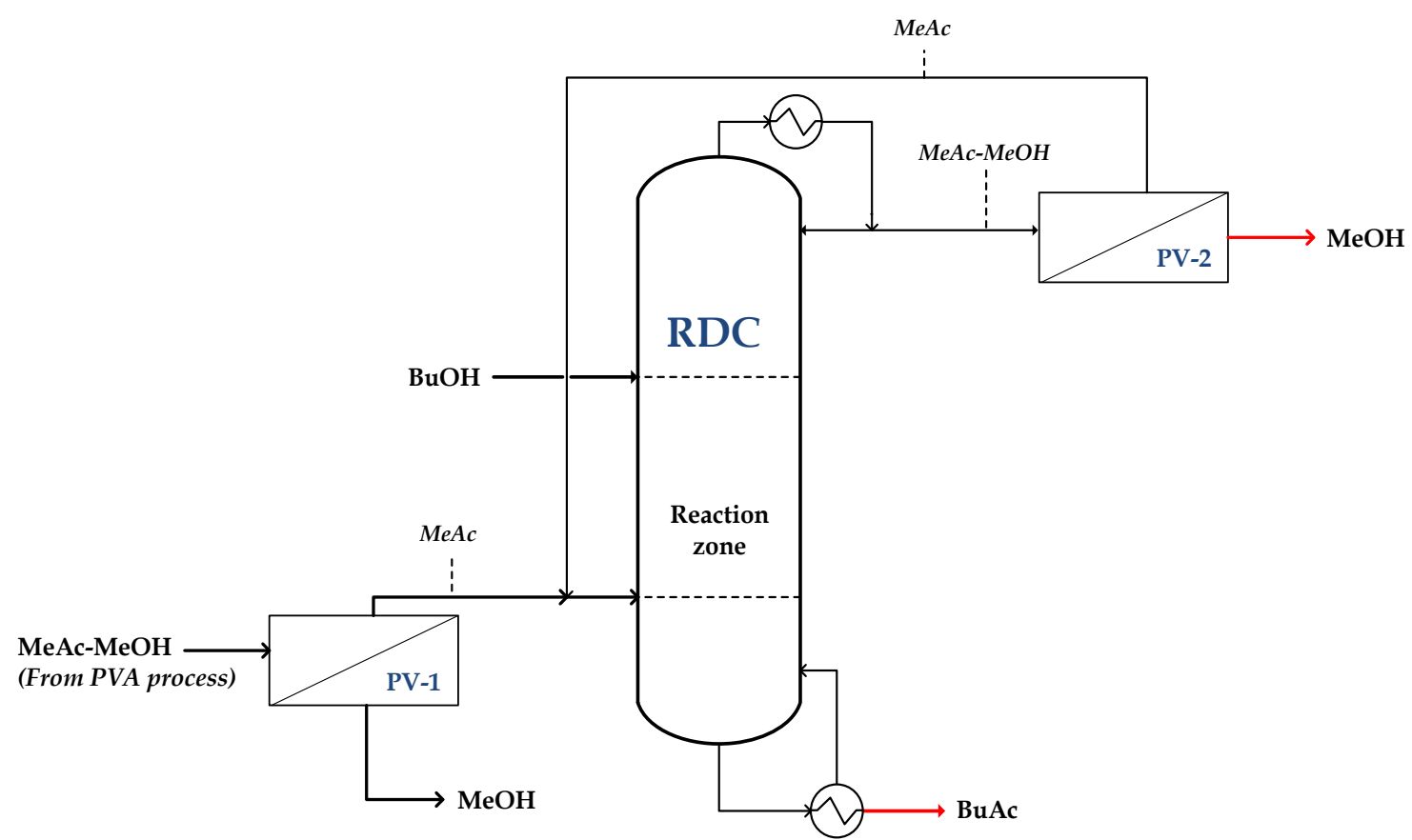

Fig. 13. The retrofit design of MM20 utilization from the polyvinyl alcohol industry by applying hybrid reactive distillation with high selectivity pervaporation.

\section{Conclusions}

This work successfully designed and optimized a hybrid reactive distillation system with a high selectivity pervaporation membrane to separate a methanol-methyl acetate azeotrope in the recycle stream. Notably, the proposed configuration eliminates the hitherto required methanol column used in conventional reactive distillation systems, since methanol can be fully removed by the pervaporation membrane, the result of which leads to less energy consumption than the distillation column. High energy and cost savings of the proposed hybrid process are obtained by optimization of the process using the Aspen Plus software package. Finally, this work showed that the proposed hybrid process could be implemented effectively with the transesterification reaction to produce butyl acetate; indeed, this new 
configuration is projected to reduce total annual costs up to $60 \%$ relative to a benchmark system. Further, this approach possesses significant commercial advantages by using methyl acetate residue from polyvinyl alcohol industrial plants, which will be aided by the use of high selectivity membranes required for butyl acetate production.

\section{Acknowledgements}

This research was supported by the Basic Science Research Program through the National Research Foundation of Korea (NRF) funded by the Ministry of Education (2015R1D1A3A01015621) and by the Priority Research Centers Program through the

National Research Foundation of Korea (NRF) funded by the Ministry of Education (2014R1A6A1031189).

\section{References}

[1] C. Le Berre, P. Serp, P. Kalck, G.P. Torrence, Acetic Acid, Ullmann's Encyclopedia of Industrial Chemistry, Wiley-VCH Verlag GmbH \& Co. KGaA2000.

[2] K. Liu, Z. Tong, L. Liu, X. Feng, Separation of organic compounds from water by pervaporation in the production of $n$-butyl acetate via esterification by reactive distillation, Journal of Membrane Science, 256 (2005) 193-201.

[3] Chemical Economics Handbook Report, Plasticizer Alcohols, SRI Consulting, Englewood, CA, USA, 2009, pp. 28.

[4] R.C. Larock, Comprehensive organic transformations: a guide to functional group preparations, Wiley-VCH New York1999. 
[5] D.-J. Tao, Y.-T. Wu, Z. Zhou, J. Geng, X.-B. Hu, Z.-B. Zhang, Kinetics for the Esterification Reaction of n-Butanol with Acetic Acid Catalyzed by Noncorrosive Brønsted Acidic Ionic Liquids, Industrial \& Engineering Chemistry Research, 50 (2011) 1989-1996.

[6] L. Jiménez, J. Costa-López, The Production of Butyl Acetate and Methanol via Reactive and Extractive Distillation. II. Process Modeling, Dynamic Simulation, and Control Strategy, Industrial \& Engineering Chemistry Research, 41 (2002) 6735-6744.

[7] Y. Fuchigami, Hydrolysis of Methyl Acetate in Distillation Column Packed with Reactive Packing of Ion Exchange Resin, Journal of Chemical Engineering of Japan, 23 (1990) 354359.

[8] Y.-D. Lin, J.-H. Chen, J.-K. Cheng, H.-P. Huang, C.-C. Yu, Process alternatives for methyl acetate conversion using reactive distillation. 1. Hydrolysis, Chemical Engineering Science, 63 (2008) 1668-1682.

[9] Y.D.C. Lin, J.H.; Huang, H.; Yu, C., Process Alternative for Methyl Acetate Conversion Using Reactive Distillation: Transesterification Versus Hydrolysis, AICHE Annual MeetingSan Francisco, 2006.

[10] B. Van der Bruggen, P. Luis, Pervaporation as a tool in chemical engineering: a new era?, Current Opinion in Chemical Engineering, 4 (2014) 47-53.

[11] L. Jiménez, A. Garvín, J. Costa-López, The Production of Butyl Acetate and Methanol via Reactive and Extractive Distillation. I. Chemical Equilibrium, Kinetics, and MassTransfer Issues, Industrial \& Engineering Chemistry Research, 41 (2002) 6663-6669.

[12] S. Steinigeweg, J. Gmehling, Transesterification processes by combination of reactive distillation and pervaporation, Chemical Engineering and Processing: Process Intensification, 43 (2004) 447-456. 
[13] E. Bożek-Winkler, J. Gmehling, Transesterification of Methyl Acetate and n-Butanol Catalyzed by Amberlyst 15, Industrial \& Engineering Chemistry Research, 45 (2006) 66486654.

[14] W.L. Luyben, K.M. Pszalgowski, M.R. Schaefer, C. Siddons, Design and Control of Conventional and Reactive Distillation Processes for the Production of Butyl Acetate, Industrial \& Engineering Chemistry Research, 43 (2004) 8014-8025.

[15] S.-J. Wang, D.S.H. Wong, S.-W. Yu, Design and control of transesterification reactive distillation with thermal coupling, Computers \& Chemical Engineering, 32 (2008) 30303037.

[16] Z. Švandová, J. Markoš, Theoretical study on transesterification in a combined process consisting of a reactive distillation column and a pervaporation unit, Chemical Papers, 65 (2011) 167-176.

[17] A. Arpornwichanop, K. Koomsup, W. Kiatkittipong, P. Praserthdam, S. Assabumrungrat, Production of n-butyl acetate from dilute acetic acid and n-butanol using different reactive distillation systems: Economic analysis, Journal of the Taiwan Institute of Chemical Engineers, 40 (2009) 21-28.

[18] H. Abdallah, A. El-Gendi, E. El-Zanati, T. Matsuura, Pervaporation of methanol from methylacetate mixture using polyamide- 6 membrane, Desalination and Water Treatment, 51 (2013) 7807-7814.

[19] R. Taylor, R. Krishna, Modelling reactive distillation, Chemical Engineering Science, 55 (2000) 5183-5229.

[20] W.L. Luyben, C.-C. Yu, Reactive distillation design and control, John Wiley \& Sons2009.

[21] R. Schefflan, Teach Yourself the Basics of Aspen Plus, John Wiley \& Sons, Inc., Hoboken, New Jersey, 2011. 
[22] D.S. Abrams, J.M. Prausnitz, Statistical thermodynamics of liquid mixtures: A new expression for the excess Gibbs energy of partly or completely miscible systems, AIChE Journal, 21 (1975) 116-128.

[23] A. Jonquières, R. Clément, P. Lochon, J. Néel, M. Dresch, B. Chrétien, Industrial stateof-the-art of pervaporation and vapour permeation in the western countries, Journal of Membrane Science, 206 (2002) 87-117.

[24] F. Lipnizki, R.W. Field, P.-K. Ten, Pervaporation-based hybrid process: a review of process design, applications and economics, Journal of Membrane Science, 153 (1999) 183210.

[25] G.R. Harvianto, F. Ahmad, L.C. Nhien, M. Lee, Vapor permeation-distillation hybrid processes for cost-effective isopropanol dehydration: modeling, simulation and optimization, Journal of Membrane Science, 497 (2016) 108-119.

[26] V. Van Hoof, L. Van den Abeele, A. Buekenhoudt, C. Dotremont, R. Leysen, Economic comparison between azeotropic distillation and different hybrid systems combining distillation with pervaporation for the dehydration of isopropanol, Separation and Purification Technology, 37 (2004) 33-49.

[27] P. Lutze, A. Gorak, Reactive and membrane-assisted distillation: Recent developments and perspective, Chemical Engineering Research and Design, 91 (2013) 1978-1997.

[28] J. Holtbrügge, A.K. Kunze, A. Niesbach, P. Schmidt, R. Schulz, D. Sudhoff, M. Skiborowski, P. Lutze, A. Górak, Reactive and Membrane-Assisted Separations, Walter de Gruyter GmbH \& Co KG2016.

[29] S. Sain, S. Dinçer, Ö.T. Savaşçy1, Pervaporation of methanol-methyl acetate binary mixtures, Chemical Engineering and Processing: Process Intensification, 37 (1998) 203-206. 
[30] D. Gorri, R. Ibáñez, I. Ortiz, Comparative study of the separation of methanol-methyl acetate mixtures by pervaporation and vapor permeation using a commercial membrane, Journal of Membrane Science, 280 (2006) 582-593.

[31] X. Tong-Hu, X. Xiao-Li, Q. Hai-Jiao, Y. Xiao-Gang, Z. Rui-Feng, Zeolite 4AIncorporated Polymeric Membranes for Pervaporation Separation of Methanol-Methyl Acetate Mixtures, Journal of Inorganic and Organometallic Polymers and Materials, 21 (2011) 816-822.

[32] G. Genduso, A. Amelio, E. Colombini, P. Luis, J. Degrève, B. Van der Bruggen, Retrofitting of extractive distillation columns with high flux, low separation factor membranes: A way to reduce the energy demand?, Chemical Engineering Research and Design, 109 (2016) 127-140.

[33] G. Genduso, P. Luis, B. Van der Bruggen, Overcoming any configuration limitation: an alternative operating mode for pervaporation and vapour permeation, Journal of Chemical Technology \& Biotechnology, 91 (2016) 948-957.

[34] W. Kujawski, M. Waczyński, M. Lasota, Pervaporation Properties of Dense Polyamide6 Membranes in Separation of Water-Ethanol Mixtures, Separation Science and Technology, 31 (1996) 953-963.

[35] R.W. Tock, J. Yu Cheung, R.L. Cook, Dioxane-Water Transport through Nylon 6 Membranes, Separation Science, 9 (1974) 361-379.

[36] R.Y.M. Huang, A. Moreira, R. Notarfonzo, Y.F. Xu, Pervaporation separation of acetic acid-water mixtures using modified membranes. I. Blended polyacrylic acid (PAA)-nylon 6 membranes, Journal of Applied Polymer Science, 35 (1988) 1191-1200.

[37] A.T. El-Gendi, S.A. Ahmed, H.A. Talaat, Preparation and evaluation of flat membranes for phenols separation, Desalination, 206 (2007) 226-237. 
[38] A. El-Gendi, H. Abdallah, Selectivity performance for polyamide-6 membranes using pervaporation of water/methanol mixtures, Desalination and Water Treatment, 51 (2013) $3263-3272$.

[39] R. Kopeć, M. Meller, W. Kujawski, J. Kujawa, Polyamide-6 based pervaporation membranes for organic-organic separation, Separation and Purification Technology, 110 (2013) 63-73.

[40] S.-J. Wang, H.-P. Huang, C.-C. Yu, Design and Control of a Heat-Integrated Reactive Distillation Process to Produce Methanol and n-Butyl Acetate, Industrial \& Engineering Chemistry Research, 50 (2011) 1321-1329.

[41] AMBERLYST 15DRY Industrial Grade Strongly Acidic Catalyst, Rohm and Haas Company, 2006.

[42] K.I.M. Al-Malah, Aspen Plus: Chemical Engineering Applications, Wiley2016.

[43] R.M. Ignat, A.A. Kiss, Optimal design, dynamics and control of a reactive DWC for biodiesel production, Chemical Engineering Research and Design, 91 (2013) 1760-1767.

[44] A.A. Kiss, R.M. Ignat, Enhanced methanol recovery and glycerol separation in biodiesel production - DWC makes it happen, Applied Energy, 99 (2012) 146-153.

[45] A.A. Kiss, D.J.P.C. Suszwalak, Enhanced bioethanol dehydration by extractive and azeotropic distillation in dividing-wall columns, Separation and Purification Technology, 86 (2012) 70-78.

[46] R.K. More, V.K. Bulasara, R. Uppaluri, V.R. Banjara, Optimization of crude distillation system using aspen plus: Effect of binary feed selection on grass-root design, Chemical Engineering Research and Design, 88 (2010) 121-134.

[47] E.J. Sheu, A. Mitsos, Optimization of a hybrid solar-fossil fuel plant: Solar steam reforming of methane in a combined cycle, Energy, 51 (2013) 193-202. 
[48] A.A. Kiss, R.M. Ignat, Innovative single step bioethanol dehydration in an extractive dividing-wall column, Separation and Purification Technology, 98 (2012) 290-297.

[49] G.R. Harvianto, K.J. Kang, M. Lee, Process Design and Optimization of an Acetic Acid Recovery System in Terephthalic Acid Production via Hybrid Extraction-Distillation Using a Novel Mixed Solvent, Industrial \& Engineering Chemistry Research, (2017).

[50] F. Lipnizki, J. Olsson, G. Trägårdh, Scale-up of pervaporation for the recovery of natural aroma compounds in the food industry Part 2: optimisation and integration, Journal of Food Engineering, 54 (2002) 197-205.

[51] W. Ji, A. Hilaly, S.K. Sikdar, S.-T. Hwang, Optimization of multicomponent pervaporation for removal of volatile organic compounds from water, Journal of Membrane Science, 97 (1994) 109-125.

[52] M.A. Harmer, Industrial processes using solid acid catalysts, Blackwell Publishers: London2002.

[53] Z. Zhang, Q. Zhang, G. Li, M. Liu, J. Gao, Design and control of methyl acetatemethanol separation via heat-integrated pressure-swing distillation, Chinese Journal of Chemical Engineering, 24 (2016) 1584-1599.

[54] P. Langston, N. Hilal, S. Shingfield, S. Webb, Simulation and optimisation of extractive distillation with water as solvent, Chemical Engineering and Processing: Process Intensification, 44 (2005) 345-351.

[55] J. Meier-Haack, W. Lenk, S. Berwald, T. Rieser, K. Lunkwitz, Influence of thermal treatment on the pervaporation separation properties of polyamide- 6 membranes, Separation and Purification Technology, 19 (2000) 199-207.

[56] J. Meier-Haack, W. Lenk, D. Lehmann, K. Lunkwitz, Pervaporation separation of water/alcohol mixtures using composite membranes based on polyelectrolyte multilayer assemblies, Journal of Membrane Science, 184 (2001) 233-243. 
[57] W. Lenk, J. Meier-Haack, Polyelectrolyte multilayer membranes for pervaporation separation of aqueous-organic mixtures, Desalination, 148 (2002) 11-16.

[58] R.Y.M. Huang, J.-J. Shieh, Crosslinked blended poly(vinyl alcohol)/N-methylol nylon-6 membranes for the pervaporation separation of ethanol-water mixtures, Journal of Applied Polymer Science, 70 (1998) 317-327.

[59] J.-J. Shieh, R.Y.M. Huang, Preparation of N-methylol nylon-6 membranes for pervaporation of ethanol-water mixtures, Journal of Applied Polymer Science, 64 (1997) $855-863$ 